\title{
Impairment of Renal Function in Eclampsia
}

\author{
FAHMIDA KHAN ${ }^{1}$, M. MUHIBUR RAHMAN ${ }^{2}$, KAZI SHAHNOOR ALAM $^{2}$, SHILA RANI DAS $^{3}$
}

\begin{abstract}
:
Objective: Aim of the study is to identify changes that occur in renal function in eclampsia patients and to determine the effect of impaired renal function on pregnancy outcome

Materials and Methods: This cross-sectional study on the impairment of renal function in eclamptic patients was carried out in the Eclampsia ward of Dhaka Medical College Hospital from July 2009 to December 2009. Study group comprised of 50 diagnosed cases of eclampsia and 50 patients with uncomplicated pregnancy was taken as control.

Results: In this study $30 \%$ of the eclamptic patients were found to have impairment of renal function. Incidence of impaired renal function was significantly increased among the patients $>25$ years of age. Multigravida eclamptic patients were found to be more prone to develop impaired renal function compared to primigravida patients. Blood pressure was significantly increased and platelet count was significantly low in the impaired renal function group of eclamptic patients compared to the normal renal function group. Incidence of foetal complications was significantly higher among the patients with impaired renal function. The eclamptic patients who had proteinuria of $>1 \mathrm{gm}$ in 24 hours had more foetal complications than those who had protienuria of $<1 \mathrm{gm} /$ day.

Conclusion: It has been observed that impairment of renal function is common among the patients with eclampsia. So, special attention should be paid to assess renal function in this group of patient
\end{abstract}

\section{Introduction:}

Eclampsia is defined as the presence of convulsions in a woman with pre-eclampsia. In different studies ${ }^{1,2,3}$ conducted in Dhaka Medical College Hospital the incidence of eclampsia has been found to be $4-9 \%$ among the patients admitted in the obstetric wards. Eclampsia is an important cause of maternal and perinatal mortality and morbidity. In Bangladesh, the obstetric causes contributed $70 \%$ of the total maternal mortality among which $11 \%$ were due to eclampsia 4 . The most common causes of maternal mortality in eclampsia are cerebrovascular accident, pulmonary edema, post-partum shock, renal failure and sepsis. The main causes of foetal death in eclampsia are prematurity, foetal asphyxia and acidosis ${ }^{5}$.

Renal involvement varies from mild changes to severe damage and the characteristic lesion range from simple ischaemia to patchy or complete tubular or cortical necrosis. In a study it was found that the renal failure was the cause of $7.5 \%$ of all maternal deaths due to eclampsia in Dhaka Medical College Hospital ${ }^{6}$. In another study the incidence of eclampsia patients having impaired renal function was found to be $10 \%$ in Dhaka Medical College Hospital ${ }^{7}$.

the effect of impaired renal function on pregnancy outcome in teaching hospital.

Widespread disturbance of the maternal vascular endothelium is responsible for the hypertension, altered vascular reactivity, activation of the coagulation cascade and the multisystem damage which accompany pre-eclampsia. The characteristic renal lesion of pre-eclampsia "glomeruloendotheliosis" is manifested primarily by swelling of the glomerular capillary endothelial cells. The hematological changes of pre-eclampsia are thrombocytopenia and microangiopathic haemolytic anaemia for which endothelial dysfunction is thought to be responsible ${ }^{8,9}$. This study is carried out to identify changes that occur in renal function in eclampsia patients and to determine the effect of impaired renal function on pregnancy outcome.

1. National Institue of Cancer Research and Hospital

2. National Institute of Kidney Disease and Urology

3. Faridpur Medical College Hospital 


\section{Materials and Methods:}

This cross-sectional study done in the Dhaka Medical College Hospital from July 2009 to December 2009. During the study period, a total of 3894 non-eclamptic patients and 403 eclamptic patients were admitted in the Department of Obstetrics and Gynaecology in Dhaka Medical College Hospital. From the eclamptic group, 50 diagnosed eclampsia patients were selected at random. From the 3894 non-eclamptic patients, 50 patients matched by parity and ages were selected at random as the control group. Those patients who were known cases of Essential hypertension, Diabetes mellitus, Chronic renal disease, Liver disease, Epilepsy, Psychiatric problems and patients who were incompletely investigated were excluded. All relevant histories were documented and similar investigations were done in both the groups. For data collection a pre-designed protocol was used to record the information. It has covered the predisposing factors (age, parity, socioeconomic background etc.), antenatal visits, gestational age, time of first convulsion, number of convulsions, interval between convulsion and hospital admission etc. Information was collected from clinical history given by the attendants in case of the study group and directly from the patients themselves in the control group. A thorough clinical examination was done. Further information was obtained by doing laboratory investigations. The data collected were compiled with the help of a personal computer and appropriate statistical analysis was carried out using SPSS program. Student's t test and Chi-square test were done to compare the results between the different groups. The difference was considered significant when the $p$ value was $<0.05$. The results are shown in the form of tables and chart in the following section.

\section{Results:}

The incidence of eclampsia was found to be $9.38 \%$ during the study period. Types of eclampsia were antepartum (72\%), intrapartum (12\%) and postpartum (16\%). Mean age of the patients in the study group was 23.6 \pm 6.2 years and that of the control group was 23.9 \pm 5.7 . There was no significant difference in the age distribution between these two groups $(p=0.9)$. In the impaired renal function group of eclamptic patients $46.6 \%$ was above 25 years of age in contrast to $11.5 \%$ of the patients in the normal renal function group $(p<0.05)$. There was statistically significant difference $(p=0.004 \& 0.005)$ both in the systolic and diastolic blood pressure between the study and the control group.

All the patients in the study group had detectable proteinuria and $54 \%$ of the patients had more than $2+$ proteinuria. In contrast $86 \%$ of the patients in the control group had no proteinuria, $12 \%$ had $1+$ proteinuria and only 1 patient had $2+$ proteinuria. The blood urea nitrogen, serum creatinine, serum uric acid and 24 hours urinary total protein were significantly higher in the study group(Table I). This study shows that out of 50 cases $70 \%$ of the patients had normal renal function and $30 \%$ had impaired renal function (serum creatinine level $>0.9 \mathrm{mg} / \mathrm{dl}$ and blood urea nitrogen $>13 \mathrm{mg} / \mathrm{dl}$ ) (Fig.-1). It is evident from this study that $93.3 \%$ of the patients with impaired renal function and $57.1 \%$ of the patients with normal renal function of the study group was from the lower socioeconomic status $(p<0.05)$.

Table-I

Comparison of renal function between the study and control group (on admission)

\begin{tabular}{lccc}
\hline Parameters & $\begin{array}{c}\text { Study group } \\
(\mathrm{n}=50) \\
\text { Mean } \pm \text { SD }\end{array}$ & $\begin{array}{c}\text { Control group } \\
(\mathrm{n}=50) \\
\text { Mean } \pm \text { SD }\end{array}$ & $\begin{array}{c}\mathrm{P} \\
\text { value }\end{array}$ \\
\hline BUN $(\mathrm{mg} / \mathrm{dl})$ & $11.26 \pm 5.64$ & $8.73 \pm 2.75$ & 0.004 \\
Creatinine $(\mathrm{mg} / \mathrm{dl})$ & $0.87 \pm 0.33$ & $0.71 \pm 0.12$ & 0.009 \\
Uric acid $(\mathrm{mg} / \mathrm{dl})$ & $6.88 \pm 1.89$ & $3.97 \pm 0.8$ & 0.005 \\
UTP $(\mathrm{g} / 24 \mathrm{hr})$ & $2.51 \pm 2.18$ & $0.27 \pm 0.11$ & 0.001 \\
UTV $(\mathrm{ml} / 24 \mathrm{hr})$ & $1515.2 \pm 854.01484 \pm 359.6$ & 0.41 \\
\hline
\end{tabular}

$35,70 \%$

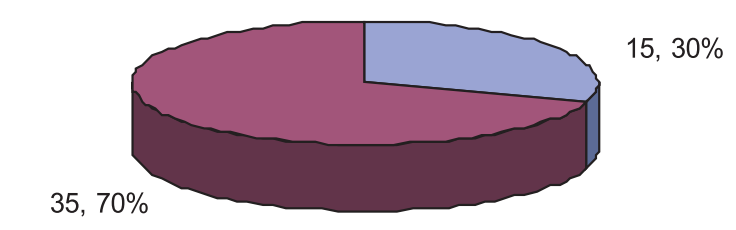

Impaired renal function Normal renal function

Renal Function Status

Fig.-1: Pie chart showing renal function status of study populations.

More than half (66.6\%) of the patients with impaired renal function were multi-gravida in contrast to $20 \%$ of the patients with normal renal function, which was statistically significant. 
In the control group $56 \%$ of the patients and in the study group only $16 \%$ of the patients had 3 or more antenatal visits. There was no significant difference in the antenatal care between the patients with impaired renal function and normal renal function of the study group. Both systolic and diastolic blood pressure was significantly higher among the impaired renal function group $(\mathrm{SBP}=161.33 \pm 28.9 \mathrm{mmHg}, \mathrm{DBP}=107.33 \pm$ $18.6 \mathrm{mmHg}$ ) than the normal renal function group $(\mathrm{SBP}=146.77 \pm 14.17 \mathrm{mmHg}, \mathrm{DBP}=98.47 \pm 8.48$ $\mathrm{mmHg})(\mathrm{P}=<0.05)$. Platelet count was significantly lower in the impaired renal function group $(136115 \pm 54646 / \mathrm{cmm})$ compared to the normal renal function group $(217410 \pm 97545 / \mathrm{cmm})$ of the eclamptic patients $(p=0.01)$. Blood urea nitrogen, serum creatinine, serum uric acid and 24 hours urinary total protein were significantly higher and urinary volume was significantly decreased in the impaired renal function group (Table-II).

More than half (68\%) of the patients in the study group had foetal complications, in contrast only $26 \%$ of the patients in the control group had such complications.
Foetal complication was significantly higher among the patients with impaired renal function group. More than one third (40\%)of the patients with impaired renal function had still birth compared to only $8.6 \%$ of the patients with normal renal function (Table-III).

Foetal complication was higher in the patients with higher level of proteinuria. 27 patients (54\%) had proteinuria of more than $1 \mathrm{gm}$ and of them 22 patients, $81.5 \%$ had foetal complications (Table-IV). The number of foetal complications was higher in the patients with serum uric acid level above $6 \mathrm{mg} / \mathrm{dl}$ though the difference was not statistically significant. Out of 9 still birth, 8 cases had uric acid level $>6 \mathrm{mg} / \mathrm{dl}$.

Most of the patients (86.6\%) with impaired renal function had antepartum eclampsia. This study found that $73.3 \%$ of the patients with impaired renal function group had onset of convulsion at or <36 weeks' gestation whereas $71.4 \%$ of the patients with normal renal function had onset of convulsion at e"37 weeks' gestation. Maternal complication was observed in 11 eclamptic patients (22\%) in this study (Table-V).

Table-II

Comparison of renal function between the impaired and normal renal function group of the eclampsia patients $(n=50)$

\begin{tabular}{|c|c|c|c|c|c|}
\hline Parameters & $\begin{array}{c}\text { Impaired } \\
\text { function }(n=15) \\
\text { Mean } \pm \text { SD }\end{array}$ & $\begin{array}{l}\text { renal } \\
\text { group }\end{array}$ & $\begin{array}{c}\text { Normal } \\
\text { function }(n=35) \\
\text { Mean } \pm \text { SD }\end{array}$ & $\begin{array}{l}\text { renal } \\
\text { group }\end{array}$ & $P$ value \\
\hline Blood urea nitrogen(mg/dl) & $15.64 \pm 6.38$ & & $8.15 \pm 3.28$ & & 0.004 \\
\hline Serum creatinine $(\mathrm{mg} / \mathrm{dl})$ & $1.24 \pm 0.33$ & & $0.72 \pm 0.09$ & & 0.003 \\
\hline Serum uric acid (mg/dl) & $8.5 \pm 1.83$ & & $6.09 \pm 1.35$ & & 0.01 \\
\hline Total urinary protein (g/24hr) & $2.71 \pm 0.92$ & & $1.67 \pm 1.03$ & & 0.02 \\
\hline Urinary volume (ml/24hr) & $487 \pm 223$ & & $1541 \pm 849$ & & 0.001 \\
\hline
\end{tabular}

Table-III

Comparison of foetal outcome between the impaired and normal renal function groups of eclampsia patients $(n=50)$

\begin{tabular}{lccc}
\hline Foetal outcome & $\begin{array}{c}\text { Impaired renal } \\
\text { function group }(\mathrm{n}=15) \\
\text { No of patients(\%) }\end{array}$ & $\begin{array}{c}\text { Normal renal function } \\
\text { group }(\mathrm{n}=35) \\
\text { No of patients(\%) }\end{array}$ & P value \\
\hline Mature live birth & $2(13.3)$ & $14(40)$ & $<.05$ \\
Fetal Complications & $13(86.7)$ & $21(60)$ & $<.05$ \\
IUGR & $3(20.0)$ & $9(25.7)$ & \\
Premature & $4(26.7)$ & $7(20)$ & \\
Stilllbirth & $6(40.0)$ & $3(8.6)$ & \\
Neonatal death & $0(0)$ & $2(5.7)$ & \\
\hline
\end{tabular}


Table-IV

Relationship between foetal outcome and level of proteinuria in eclampsia patients $(n=50)$

\begin{tabular}{lcccc}
\hline Foetal outcome & \multicolumn{4}{c}{ 24 hours urinary total protein } \\
\cline { 2 - 5 } & $0.3-1 \mathrm{gm}$ & $>1-<3 \mathrm{gm}$ & $3-5 \mathrm{gm}$ & $\mathrm{e}$ "5 gm \\
\hline Mature live birth & 11 & 3 & 2 & 0 \\
Fetal Complications & 12 & 15 & 1 & 6 \\
IUGR & 5 & 5 & 1 & 1 \\
Premature & 5 & 3 & 0 & 3 \\
Stillbirth & 1 & 6 & 0 & 2 \\
Neonatal death & 1 & 1 & 0 & 0 \\
\hline
\end{tabular}

Table-V

Maternal complications of the impaired and normal renal function goups of eclampsia patients $(n=50)$.

\begin{tabular}{lcc}
\hline Maternal Complications & $\begin{array}{c}\text { Impaired renal function group }(\mathrm{n}=15) \\
\text { No. of patients }\end{array}$ & $\begin{array}{c}\text { Normal renal function group }(\mathrm{n}=35) \\
\text { No. of patients }\end{array}$ \\
\hline Severe renal failure & 1 & 0 \\
Postpartum haemorrhage & 1 & 1 \\
Retained placenta & 1 & 0 \\
Cervical tear & 1 & 1 \\
Wound infection & 1 & 3 \\
Death & 1 & 0 \\
\hline
\end{tabular}

\section{Discussion:}

Eclampsia is a multi-system disease and impairment of renal function is one of the major complications of eclampsia which increases foetal complications and maternal morbidity and mortality.It is still one of the leading causes of both maternal and perinatal mortality and morbidity in Bangladesh ${ }^{4}$.

Renal involvement in preeclampsia and eclampsia has been observed by many observers ${ }^{15,16}$. A number of pathological changes, which tend to parallel in severity of the clinical condition, occur in the kidney. During the study period, the incidence of eclampsia was found to be $9.38 \%$ in this study. Some previous studies showed incidence of eclampsia in Dhaka Medical College Hospital as $8.6 \%, 4.14 \%, 7-10 \%$ of obstetric cases $^{1,6}$. In this study $72 \%$ of the eclamptic patients had antepartum eclampsia which is the commonest type of eclampsia as shown in different studies ${ }^{14}$. Katz V.L et al studied 53 pregnancies complicated by eclampsia in two tertiary centers in North Carolina USA and found that $53 \%$ of them had antepartum seizures, $36 \%$ had intrapartum and $11 \%$ had postpartum seizures ${ }^{15}$. Like other studies most of the eclamptic patients $(66 \%)$ in this study were primigravida.

Both systolic and diastolic blood pressure was significantly higher in the study group compared to the control group. Significant difference in renal function was observed between the study and control group in this study. Mean 24 hours urinary total protein in the study group was $2.51 \pm 2.18 \mathrm{gm}$ which was significantly higher than the mean 24 hour urinary total protein in the control group which was $0.27 \pm 0.11 \mathrm{gm}(p<0.001)$. All patients in the study group had significant proteinuria ( $>300 \mathrm{mg} / 24$ hours) in this study and only 2 patients had significant proteinuria in the control group. Mean serum uric acid level was significantly higher in the study group $(6.88 \pm 1.89)$ compared to the control group $(3.97 \pm 0.8)(p<0.01)$. Higher serum uric acid level in the eclamptic patients has also been observed by other investigators ${ }^{17,18}$.

In this study 15 patients (30\%) in the study group had impaired renal function (Serum creatinine $>0.9 \mathrm{mg} / \mathrm{dl}$ and blood urea nitrogen $>13 \mathrm{mg} / \mathrm{dl}$ ). MacKay A.P et al found impaired renal function in $15 \%$ of the eclamptic patients ${ }^{17}$ but Sibai B M et al reported that $48 \%$ of the patients with eclampsia had impaired renal function ${ }^{19}$. 
Nearly half $(46.6 \%)$ of the patients in the impaired renal function group was $>25$ years of age whereas only $11.5 \%$ of the patients in the normal renal function group was $>25$ years of age $(p<0.01)$. Of 6 eclamptic patients above 30 years of age 5 patients (83.3\%) had impaired renal function. This may be due to decrease in renal reserve with increasing age.

More than half $(67.3 \%)$ of patients in the impaired renal function group were multigravida compared to only $20 \%$ of patients in the normal renal function group $(p<0.05)$. So it appears from these results that multigravida eclamptic patients are at risk of developing impairment of renal function. Lack of antenatal care is a recognized risk factor for eclampsia. However, there was no significant difference in the number of unbooked patients between the impaired renal function group and normal renal function group of the eclamptic patients in this study.

Systolic and diastolic blood pressure in the impaired renal function group were significantly higher than the systolic and diastolic blood pressure of normal renal function group $(p<0.05)$ and platelet count was significantly lower in the impaired renal function group compared to the normal renal function group $(p<0.01)$. Out of 15 patients with impaired renal function 14 patients (93.3\%) had thrombocytopenia (platelet count $<150,000 / \mathrm{cmm}$ ). Activation of haemostatic system has been documented in eclampsia and its most common manifestation is thrombocytopenia. Toxaemia has been thought of a disease in which there is abnormal platelet vessel wall interaction. There was also significant difference in the serum uric acid level between the impaired renal function group and the normal renal function group. Similar observation was also made by Sibai B.M et al ${ }^{19}$. As like this study, they found that the eclamptic patients with renal impairment had significantly more proteinuria than the eclamptic patients with normal renal function. So degree of proteinuria may act as a predictor for impaired renal function in the patients with eclampsia.

When impaired renal function and normal renal function group of the eclamptic patients were compared, $86.7 \%$ of the impaired renal function group had foetal complication compared to $60 \%$ of the normal renal function group $(p<0.05)$. So impairment of renal function contributed to increased number of foetal complication.Similar findings has also been reported by other investigators ${ }^{17}$.
Relationship of foetal complication with proteinuria was analyzed. 23 eclamptic patients had proteinuria $<1 \mathrm{gm} /$ day and of them 12 patients (52.1\%) had foetal complications. On the other hand, 27 patients had proteinuria $>1 \mathrm{gm} /$ day and of them 22 patients $(81.5 \%)$ had foetal complications $(p<0.05)$. So, foetal complications were significantly higher in the eclamptic patients with urinary total protein $>1 \mathrm{gm} /$ day. In a study done by Ferrazzani S.et al on 444 hypertensive pregnant women, increase proteinuria predicted an adverse pregnancy outcome.

Maternal complication was observed in 11 eclamptic patients (22\%) in this study.

\section{Conclusion:}

Impairment of renal function is common among the patients with eclampsia. The risk factors which may predispose the eclamptic patients to impaired renal function are age above 25 years, multigravida, antepartum eclampsia, onset of convulsion at or before 36 weeks of gestation, increased level of proteinuria and thrombocytopenia. So special attention should be paid assess renal function in these patients.

\section{Reference:}

1. Begum F, Ara I: Management and outcome of eclampsia in a teaching hospital.J Postgrad Med Res.1995; 10(1): 17-21

2. Begum F: Management of eclampsia (Dissertation).Bangladesh College of Physicians and Surgeons,Dhaka.1987; P-79

3. Khatoon S, Chowdhury SF: Study of patients suffering from eclampsia with renal function impairment.Bangladesh J Obstet Gynaecol.1994; 9(1):8-15

4. WHO Practical Guide: "Mother baby package":Implementing safe motherhood in the country.1994.

5. Nahar,S: HELLP Syndrome in Eclampsia (A Thesis: BSMMU, Dhaka).1996; P-129

6. Afroz L: Analysis of causes of death in eclampsia(A dissertation BCPS, Dhaka). .1998.

7. Nahar S: Study of the relationship of different variables with fate of mother and baby in eclampsia patients (an analysis of 500 hospital admitted cases).Depart Obstet Gynaecol, Int Post Medi Research, Shahbag, Dhaka.1996. 
8. Thorburn J, Drumond MM, Woigwan KA, Lowe CDO, Forbes CD, Prentice CRM, Whitfield CR. Br J Obstet Gynaecol 1982; 84:117.

9. Siemans. Fourteen thousand teen age pregnancies. Am J Nurs 1966; 66:308-11.

10. Campell et al. Preclampsia in second pregnancy. Br J Obstet Gynaecol 1985; 93:13140.

11. Reynir A. Genetic and familial predisposition to eclampsia and preeclampsia in a defined population. Br J Obstet Gynaecol 1990; 97, 7629.

12. Khatoon S. Clinical profile and management of eclampsia in SSMC \& MH (Dissertation) Bangladesh College of Physicians, Dhaka. 1990, p-123.

13. Vinatier D, Monnier JC. Pre-eclampsia : physiology and immunological aspects. Eur J Obstet Gynecol Reprod Biol 1995; 61: 85-97.
14. Conde-Agudelo A and Belizan J.M. Risk factors for pre-eclampsia in a large cohort of Latin American and Caribbean women. Brit J Obstet Gynecol 2000; 107(1): 75-83.

15. Katz V.L, Farmer R and Kuller J.A. Preeclampsia into eclampsia: Toward a new paradigm. Am J Obstet Gynecol 2000; 182: 1389-96.

16. Dutta D.C. Text book of Obstetrics. Calcutta, New Central book agency Pvt Ltd. $3^{\text {rd }}$ Edition, 1995; 35, 52, 242.

17. MacKay A.P, Berg C.J and Atrash H.K. Pregnancy related mortality from preeclampsia and eclampsia. Obstet Gynecol 2001; 97(4): 533-8.

18. Oladokun A, Okewole A.I, Adewole I.F, Babarinsa I.A. Evaluation of cases of eclampsia in the University College Hospital, Ibadan over a 10 year period. West Afr J Med 2000; 19(3): 192-194.

19. Sibai B.M, Anderson G.D, McCubbin JH. Eclampsia II. Clinical significance of Laboratory findings. Am J Obstet Gynecol 1982, vol 59(2); 147-153. 